\title{
NILAI KARAKTER ISLAMI DALAM TUNJUK AJAR MELAYU TENAS EFFENDY
}

Griven H. Putera

Kementerian Agama Provinsi Riau

Email: grivenh.putera@gmail.com

\begin{abstract}
Tunjuk Ajar Melayu written by Tenas Effendy is a brilliant work that contains a variety of educational pearl values in a broad sense. If the value is actualized in the concepts of education, then a quality form or format will be produced in the preparation of the concept of education. One of the most urgent values in Malay teaching is character. Based on a study of the character content in the 2013 Curriculum and the character values in the Tenas Effendy Malay Language Teaching Guide, the author sees that there are similarities and meeting points of the two aspects. However, the character values in Tunjuk Ajar Melayu by Tenas Effendy are far broader and deeper and it touches directly on the cultural basis of society. These values are neatly packaged in the curriculum, they will result a very positive if these impact in the context of achieving national education goals today.
\end{abstract}

Keywords: Character Value, Tunjuk Ajar Melayu

I. Pendahuluan

Menurut Undang-undang

Sistem Pendidikan nasional, Nomor

20 Tahun 2003, pada pasal 1 ayat (1)

disebutkan bahwa pendidikan adalah usaha sadar dan terencana untuk mewujudkan suasana belajar dan proses pembelajaran agar anak didik secara aktif mengembangkan potensi dirinya untuk memiliki kekuatan spritual keagamaan, pengendalian diri, kepribadian, kecerdasan, akhlak mulia, serta keterampilan yang diperlukan dirinya, masyarakat, bangsa dan negara. Selanjutnya pada pasal (3) disebutkan bahwa pendidikan nasional berfungsi untuk mengembangkan kemampuan, dan membentuk watak serta peradaban bangsa yang bermartabat, dalam rangka mencerdaskan kehidupan bangsa.

Pada pasal 1 ayat (4), yang disebut anak didik adalah anggota masyarakat yang berusaha mengembangkan potensi diri melalui 
proses pembelajaran yang tersedia pada jalur, jenjang, jenis pendidikan. Pertanyaannya, apakan tujuan mulia pendidikan bangsa saat ini sudah terealisasi? Jawaban sementara adalah belum karena pendidikan belum menjadi wahana humanisasi bagi anak-anak didiknya bahkan sebagian menjadi tempat kekerasan (bullying) dan ketidakmanusiawian sebagian pendidik dan seniornya terhadap anak atau adik didiknya.

Rohimah M Nur (2011: 43) menyebutkan bahwa berbagai pandangan skeptis terhadap pelaksanaan pendidikan karakter di Indonesia tentu tidak terlepas dari kondisi riil yang terjadi di tengah masyarakat. Krisis moral tengah menjalar dan menjangkiti bangsa ini. Hampir semua elemen bangsa merasakannya. Misalnya, Pilkada yang ricuh, kasus korupsi dan para politisi, hingga tebar janji politik setiap kali menjelang pemilu. Sementar itu merebaknya sikap hidup pragmatik, melembaganya budaya kekerasan, atau meruyaknya bahasa ekonomi dan politik, disadari atau tidak, telah ikut melemahkan karakter anak bangsa sehingga nilai luhur baku dan kearifan sikap hidup menjadi mandul. Anak-anak muda begitu mudahnya melontarkan bahasa oral dan bahasa tubuh yang cendrung tereduksi oleh gaya ungkapan kasar dan vulgar. Nilainilai etika dan estetika telah terbonsai dan terkerdilkan oleh gaya hidup instan dan pragmatik.

\section{Menurut}

Detiknews.com (23/8/2018), bahwa KPAI menangani 1.885 kasus pada semester pertama 2018. Dari angka itu, anak berhadapan dengan hukum $(\mathrm{ABH})$ seperti jadi pelaku narkoba, mencuri, hingga asusila menjadi kasus yang paling banyak. Data KPAI menyebut ada 504 kasus $\mathrm{ABH}$, kemudian di posisi kedua ada kasus keluarga dan pengasuhan alternatif atau anak yang orangtuanya bercerai dengan 325 kasus. Posisi ketiga, pornografi dan cyber crime dengan 255 kasus. Dalam kasus ABH, kebanyakan anak masuk Lembaga Pemasyarakatan Khusus Anak (LPKA) karena mencuri sebanyak 23,9 persen. Selanjutnya, kasus narkoba 17,8 persen, kasus asusila 13,2 persen dan lainnya. 
Jurnal Ilmu Budaya, Vol. 17, No. 1 Agustus Tahun 2020

Pendidikan karakter di
Indonesia seolah telah gagal, itu
semua disebabkan di antaranya
karena nilai dan penanaman nilai
karakter bagi anak didik tidak
berangkat dari wawasan budayanya
sendirinya. Bangsa Indonesia saat
ini telah kehilangan kearifan lokal
(local wisdom) yang menjadi
karakter budaya bangsa sejak
berabad-abad lalu, padahal itu
merupakan fondasi karakter bangsa
Indonesia yang sudah teruji berabad-
abad lamanya.

Sebagai sebuah puak yang besar, Melayu telah menjadi penyumbang banyak hal bagi bangsa ini, di antaranya bahasa Melayu dikukuhkan menjadi bahasa Indonesia. Selain bahasa, budi pekerti pergaulan Melayu pun telah sedikit banyaknya membangun tata pergaulan nusantara karena pusatpusat dagang dan pemerintahan pernah ada di negeri-negeri Melayu Riau-Johor, Siak, Samudra Pasai, Malaka, Johor, Bintan, Pelalawan dan lain sebagainya. Nilai-nilai Melayu atau kearifan lokal (local wisdom) Melayu telah membangun peradaban nusantara. Untuk itu, mempertimbangkan nilai kearifan Melayu dalam membangun karakter bangsa ini hemat penulis mesti dipertimbangkan secara serius.

Salah satu aspek kehidupan orang Melayu yang juga menjadi locus khas mereka adalah cita rasa seni yang tinggi. Cita rasa seni ini tergambar dari banyaknya karyakarya yang ditinggalkan para pujangga Melayu yang dapat dinikmati pada masa sekarang. Salah satu khas kesusastraan Melayu adalah karya-karya sastra yang dihasilkan selalu kental dengan nilai Islam. Bahkan jika diteliti lebih jauh, bukan hanya karya sastra Melayu saja yang kental dengan nilai-nilai Islam melainkan seluruh aspek budaya dan kehidupan orang Melayu.

Salah satu karya besar dalam kesusastraan Melayu era kini adalah Tunjuk Ajar Melayu (TAM) Karya Tenas Effendy (TE). Salah satu karya besar Tenas Effendy yang masih sangat familiar sampai saat ini adalah Tunjuk Ajar Melayu. Buku ini mengandung ungkapan hikmah, petatah-petitih Melayu yang bersumber dari para bijak Melayu di 
masa lalu, terutama dari orang tuanya sendiri H Tengku Said Muhammad Al-Jufri dan keluarganya. sebagian lagi merupakan hasil gubahan Tenas Effendy sendiri.

Jika dilihat lebih dalam, butirbutir kata mutiara yang terdapat dalam TAM TE sangat matan berisi nilai Islam, dan juga sangat kental bermuatan nilai-nilai pendidikan Islam. TAM berisi ungkapan bijak yang bermakna tinggi dan yang merupakan pengejawantahan ajaran Islam yang terdapat dalam Alquran dan Hadist Nabi Muhammad Saw. Keindahan bahasa dan keluasan makna yang terkandung dalam TAM menunjukkan bahwa TE merupakan seorang pujangga. Dikatakan demikian karena beliau mampu menyatukan bahasa di dalam makna di mana bahasa itu sendiri mengandung dan memberikan makna yang luar biasa sehingga terbentuk rangkaian kata yang sangat indah dan bermakna dalam.

Selain bernilai dan bermakna luar biasa, TAM mengandung nilainilai pendidikan Islam yang luar biasa. Sekalipun berbentuk kata-kata indah penuh makna yang dikonotasikan dengan karya sastra, tetapi tampaknya TE memiliki maksud dan tujuan yang lebih jauh dari sekedar karya sastra. Terlihat keinginan TE yang hendak menjadikan TAM sebagai tonggak dasar orang Melayu untuk memahami Islam yang terkandung dalam Alquran dan Hadist Nabi.

Kata-kata bijak yang terdapat dalam TAM jika dilihat lebih dalam ternyata mengandung nilai-nilai dasar karakter secara universal. Mulai dari yang bersifat khusus sampai persoalan yang bersifat umum dalam berbagai aspek kehidupan individu dan masyarakat. Apabila ini dapat dielaborasi dan dianalisis secara baik, maka akan dapat melahirkan konsep dasar pendidikan karakter yang sangat bagus dalam praktik paendidikan, khususnya di Indonesia.

Fakta menunjukkan bahwa TAM TE pada masa kini hanya dilihat sebagian kalangan cuma sebagai karya sastra semata. TAM hanya dilihat sebatas jalinan katakata dan kalimat yang indah tanpa pernah memikirkan dan menggali nilai-nilai pendidikan yang 
terkandung di dalamnya. Padahal, jika nilai-nilai yang terkandung di dalam TAM diaktualisasikan secara nyata dalam kehidupan, maka akan sangat memberikan nuansa pendidikan yang sangat berharga, bukan hanya untuk kalangan Melayu tetapi juga bagi setiap orang yang mau mempelajarinya dengan baik.

Terkait dengan hal tersebut, saat ini pemerintah sedang gencarnya menggaungkan tentang pendidikan karakter. Kurikulum 2013 dengan berbagai perubahan dan perkembangannya menitikberatkan tentang pendidikan untuk membentuk karakter siswa. Berbagai konsep telah dikaji dan dimasukkan dalam Kurikulum 2013 oleh para ahli pendidikan di Indonesia. Namun demikian, konsep yang ada tentu belum final dan akan terus berkembang sesuai dengan kajian yang ada.

Berdasarkan kajian terhadap muatan akhlak atau karakter dalam Kurikulum 2013 dan nilai-nilai karakter dalam TAM karya TE, penulis melihat ada kesamaan dan titik temu dari kedua aspek tersebut. Namun demikian, nilai karakter dalam TAM karya TE jauh lebih luas dan mendalam serta menyentuh langsung ke dasar budaya masyarakat. Nilai-nilai ini apabila dikemas secara baik dalam kurikulum akan menghasilkan pengaruh yang sangat positif dalam rangka mencapai tujuan pendidikan nasional saat ini.

\section{Pembahasan}

\section{A. Kajian Terhadap Struktur Buku TAM Karya Tenas Effendy \\ Buku TAM karangan Tenas} Effendy pada dasarnya merupakan karya tulis yang menguraikan butirbutir ungkapan berbentuk syair dan pantun yang berisi nilai-nilai dasar pandangan hidup dalam budaya Melayu Riau. Karya ini terdiri dari tiga bagian besar yaitu pendahuluan, isi dan penutup. Bagian pendahuluan memberikan pemahaman kepada pembaca mengenai pengertian, kandungan, kedudukan, dan manfaat dari Tunjuk Ajar Melayu. Bagian isi dari buku "Tunjuk Ajar Melayu" yaitu terdiri dari dua pokok bahasan yaitu butir-butir Tunjuk Ajar dan Petuah dan Amanah. Pada 
Jurnal Ilmu Budaya, Vol. 17, No. 1 Agustus Tahun 2020

penjelasan mengenai butir-butir

Tujuk Ajar yaitu terdiri dari 29 tema dan 10 petuah amanah.

\section{B. Nilai-nilai}

Pendidikan

Karakter dalam Tunjuk Ajar

Melayu dan Implikasinya

terhadap

Konstruksi

\section{Pendidikan Karakter}

Secara kuantitas dan kualitas, Tunjuk Ajar Melayu (TAM) sangat luas dan banyak sekali jumlahnya. Penulis menemukan minimal 40 karakter dalam buku TAM TE. Hal itu dapat dicari dan digali dalam berbagai khazanah karya sastra lisan maupun tulisan para intelektual Melayu dari zaman ke zaman. Tak sedikit yang masih tersimpan dalam ingatan para tetua Melayu di kampung-kampung Melayu.

Sebagian para penghapal sastra lisan itu sudah tiada sehingga ini menjadi kerugian bagi dunia literasi Melayu ke depan. Akan tetapi sebagiannya sudah dituliskan para intelektual Melayu, dan dapat dibaca, seperti di antaranya buku TAM TE. Buku fenomenal ini merupakan sebutir mutiara dari jutaan mutiara petuah amanah Melayu yang ada.
Orang Melayu tidak menafikan bahwa sebelum Islam masuk ke tanah ini telah hadir beberapa agama lainnya seperti Hindu, Budha dan lain sebagainya. Akan tetapi Islam merupakan agama yang sesuai dan sempurna bagi orang Melayu. Orang yang keluar dari agama Islam tidak lagi dianggap sebagai orang Melayu. Seperti diungkapkan;

"Adat bersendi syarak, syarak bersendi kitabullah. Adat ialah syarak semata, adat semata Quran dan Sunnah, adat sebenar adat ialah Kitabullah dan Sunnah nabi, syarak mengata adat memakai, ya, kata syarak, benar kata adat. Adat tumbuh dari syarak, syarak tumbuh dari Kitabullah. Berdiri adat karena syarak".

Begitulah Melayu, puak ini demikian lekat dengan Islam, termasuk juga dalam urusan akhlak atau karakter. Nilai-nilai karakter Melayu sesunguhnya adalah nilainilai karakter Islam dan nilai-nilai asas dan nilai-nilai luhur budaya Melayu itu sendiri.

Begitu juga nilai kejujuran. Dalam perspektif Melayu, keutamaan kejujuran digambarkan Tenas Effendy (1994: 289) dalam ungkapan berikut: 
Jurnal Ilmu Budaya, Vol. 17, No. 1 Agustus Tahun 2020

\begin{tabular}{lr}
\hline Apa tanda & Melayu \\
terbilang/hatinya $\quad$ jujur \\
dadanya lapang//apa tanda \\
Melayu terbilang/jujurnya \\
sampai ke sumsum tulang// apa \\
tanda Melayu budiman/hatinya \\
jujur dibalut iman// apa tanda \\
Melayu budiman /jujur dan \\
ikhlas jadi pakaian
\end{tabular}

Ungkapan-ungkapan di atas tentu saja sejalan dengan nilai-nilai Islam di antaranya hadits nabi: "Bila berucap dusta, bila berjanji ingkar dan saat dipercaya khianat."(HR, Bukhari dan Muslim)

Begitu juga dengan nilai karakter toleransi dalam perspektif Melayu tidak jauh berbeda dengan nilai toleransi dalam Islam. TAM mengungkapkan:

apa tanda Melayu bertuah, kasih tiada memilih bangsa, sayang tiada memilih harta Apa tanda Melayu bertuah, berkasih sayang dengan hamba Allah

apa tanda Melayu berakal, kasihnya tidak mengkaji asal

Nilai karakter disiplin dalam Melayu juga tidak jauh berbeda dengan nilai Islam. Di antara ungkapan TAM TE (1994: 157) tentang disiplin adalah:

Wahai ananda kekasih ibu, bekerjalah engkau sepanjang waktu

bekerja keras janganlah malu semoga Allah meberkahi hidupти

Syair di atas berisi tentang memanfaatkan waktu untuk melakukan kerja yang bermanfaat. Kedisiplinan waktu harus dijaga karena itu bagian dari nilai agama.

Nilai karakter kerja keras dalam Tunjuk Ajar Melayu juga sejalan dengan nilai anjuran kerja keras dalam Islam. Hal ini dapat dilihat dari ungkapan Melayu, di antaranya syair berikut:

Wahai ananda peganglah
amanah,
bekerja jangan berlengah-
lengah
supaya tiadadimasukifitnah
semoga dirimu dilindungi
Allah.
Melayu amat mendorong kaumnya untuk kreatif dan jangan sampai hidup sia-sia. Tentu saja nilai ini juga merupakan nilai yang sejalan dengan Islam seperti pesan yang tersirat dalam Alquran (QS [59]:18). Bagi puak Melayu orang yang bijak adalah yang selalu kreatif, tak mau berpangku tangan. Ia mengerti betul bahwa hidup di dunia hanya sementara, untuk itu ia manfaatkan usia singkat itu untuk berbuat. Hal 
itu misalnya tampak dari ungkapan: "apa tanda orang beradat, umurnya habis ada manfaat". Dalam ungkapan lainnya:

Pisang serawak tumbuhnya subur

Buahnya banyak rasa perisa Orang bijak ingatkan umur Usianya banyak membuat jasa

Selain kreatif, puak Melayu juga dianjurkan untuk mandiri. Kemandirian bagi puak Melayu tidak datang dari kuatnya semangat dan pengalaman serta pengetahuan saja akan tetapi juga bersumber dari sikap tawakkal dan iman. Untuk itu memupuk sikap tawakkal dan meneguhkan iman menjadi sangat penting jika ingin hidup mandiri:

Pucuk putat selera putat Bunganya mekar di pagi hari Eloklah sifat orang beradat Hidup berdiri di kaki sendiri

Di samping nilai karakter kreatif, TAM TE (1994: 401) juga berbicara tentang demokratis yaitu nilai musyawarah.

Apa tanda Melayu bertuah,
duduk
bermusyawarah

Selain TAM TE berbicara tentang demokrasi dan musyawarah, juga banyak mendorong masyarakatnya untuk memupuk rasa ingin tahu agar menjadi orang cakap dan berilmu.

\section{Dalam mengaji kekurangan masa \\ Dalam menuntut kekurangan usia \\ Dalam beramal berhabis daya Dalam bekerja tiada berkira.}

TAM juga membahas tentang nilai karakter semangat kebangsaan. Salah satu ungkapan Melayu berbunyi: "Adat hidup berkaum bangsa, berkasih sayang rasa merasa".

TAM TE (1994: 122) juga mengajarkan puak Melayu agar menghargai prestasi orang lain. Akibatnya mereka tidak malu dan segan memuji, menyanjung dan belajar atau berguru kepada orang lain yang memiliki kelebihan. Hal itu dapat dilihat dari ungkapan berikut:

Wahai ananda permata ibu, menuntut ilmu janganlah malu kebodohan diri engkau mengaku

lebih orang engkau berguru

Para intelektual Melayu juga memberikan pantangan pada beberapa hal, di antaranya dapat dilihat pada ungkapan TAM TE (1994: 225) berikut: 
Malu berguru menuntut ilmu, malu bertanya kepada ulama malu menuntut kepada yang patut

malu mengaji kepada yang ahli.

Ungkapan di atas menyiratkan agar menghargai orang lain. Untuk itu tuntutlah ilmu kepada yang memiliki ilmu pengetahuan yaitu para ilmuan. Jika belum paham agama, maka bertanyalah kepada ulama. Jika tidak memahami sesuatu hal maka bertanyalah kepada ahlinya. Ini merupakan bentuk menghargai prestasi dan kelebihan orang lain. Hal ini juga amat sesuai dengan ayat Alquran (QS Al Nahl [16]: 43) "Bertanyalah kamu kepada ahli ilmu jika kamu tidak mengetahuinya”.

TAM juga memuat tentang nilai karakter bersahabat dan komunikatif dalam menjalani kehidupan, hal itu dapat dilihat dalam berbagai ungkapan bijak berikut:

Wahai ananda dengarlah peri, berkasih sayang sifat terpuji pandai-pandailah menjaga diri hati orang jangan disakiti

Demikian petuah Melayu agar selalu bersahabat dan berkomunikasi baik dengan orang lain. Menjalin hubungan baik tanpa pandang bulu, tanpa membedakan asal muasal, warna kulit, suku dan lain sebagainya.

Dalam pergaulan, puak Melayu sejatinya menjaga diri, baik lidahnya, perbuatannya dan lain sebagainya. Hal ini sesuai seperti yang diungkapkan Antar Venus (2015: 34), bahwa bagi masyarakat Melayu, tindakan membangun, memelihara atau memperbaiki hubungan atau komunikasi antarmanusia haruslah dimulai dari hati.

Adat hidup sama saudara, berkasih sayang sepanjang masa

Adat hidup sesama sahabat, berkasih sayang sampai ke lahat

Adat hidup orang budiman, kasihnya tidak memilih kawan Adat hidup orang yang soleh, kasih sayangnya tiada memilih

Hal ini juga sejalan dengan nilai Islam sebagaimana terdapat dalam Alquran (QS [16]: 97), "Barangsiapa yang mengerjakan amal soleh, baik laki-laki maupun perempuan, dalam keadaan beriman, maka sesungguhnya kami akan berikan kepadanya kehidupan yang 
baik dan sesungguhnya akan kami beri balasan kepada mereka dengan pahala yang lebih baik dari apa yang telah mereka kerjakan."

TAM juga banyak memberikan anjuran agar anak bangsanya memiliki karakter pendidikan damai, hal ini tercermin pada banyak ungkapan-ungkapan bijak.

Kalau hidup benci membenci, bangsa rusak binasalah negeri

Konsep yang ditawarkan Melayu agar muncul perdamaian adalah konsep "kasih" dan "sayang".

TAM juga memotivasi masyarakatnya agar gemar membaca. Beberapa ungkapan Melayu agar masyarakatnya gemar membaca dapat dilihat dalam isi tunjuk ajar. Hal ini termaktub dalam Tam TE (1994: 533).

Bijak membaca tanda zaman, bijak membaca peralihan bulan

Bijak membaca tanda di awan, bijak membaca tuah di badan Bijak membaca jalan kelindan, bijak membaca kayu di hutan, Bijak membaca ombak lautan

Masyarakat Melayu amat peduli dengan alam lingkungan. Dalam pandangan masyarakat Melayu, alam berupa hutan, sungai, laut dan sebagainya bukan dibiarkan begitu saja tapi boleh dimanfaatkan asal jangan dieksploitasi besarbesaran. Kekayaan alam boleh dimanfaatkan tetapi punya aturan dan batas-batas serta ketentuan masyarakat.

Apa tanda hidup menenggang, menjaga alam mengikut undang

Adat hidup orang beriman, tahu menjaga laut dan hutan tahu menjaga kayu dan kayan, tebasnya tidak menghabiskan tebangnya tidak memunahkan, bakarnya tidak membinasakan

Seorang Melayu sejati berpantang merusak alam, dan mesti menjaga serta memeliharanya dengan baik. Selain itu ia juga mesti peduli dengan kampung halamannya. Ini dapat dilihat dari beberapa ungkapan Melayu berikut:

Tanda orang memegang amanah, pantang merusak hutan dan tanah

Tanda orang berpikiran panjang, merusak alam ia berpantang

Ungkapan Melayu di atas sejalan dengan ajaran Islam, sebagaimana termaktub dalam Alquran (QS [30]: 41). "Telah tampak al-fasad (kerusakan) di darat dan di laut disebabkan karena 
Jurnal Ilmu Budaya, Vol. 17, No. 1 Agustus Tahun 2020

perbuatan tangan manusia, supaya

Allah merasakan kepada mereka sebagian dari (akibat) perbuatan mereka, agar mereka kembali (ke jalan yang benar)"

Selain peduli kepada alam lingkungan, sebagai buah dari pengamalan nilai Islam, orang Melayu pun amat peduli dengan manusia lain. Rasa kesetiakawanan sosial masyarakat Melayu begitu kuat dalam keseharian mereka. Di dalam tunjuk ajar pun muncul berbagai kata pemberi motivasi agar masyarakat Melayu peduli dengan sesama. Hal ini dapat dilihat pada TAM TE (1994: 525) berikut:

Sama sekampung tolong menolong, Sama sedusun tuntun menuntun

Sama sebanjar dengar mendengar, Sama senegeri beri memberi

Sama sebangsa rasa merasa

Ungkapan-ungkapan bijak di atas tentu saja sejalan dengan nilainilai luhur Islam, seperti salah satunya hadits nabi Muhammad Saw (HR: Muslim): "Perumpamaan orang-orang mukmin dalam hal saling kasih. Saling menyayang dan saling cinta adalah seperti satu tubuh, jika salah satu anggotanya merasa sakit, maka anggota-anggota tubuh yang lain ikut merasakan sulit tidur dan demam."

Masyarakat Melayu merupakan masyarakat yang bertanggung jawab. Selain karena dorongan fitrah yang merupakan bawaan dari Ilahi juga karena dorongan dari petuah-petuah para pendahulu. TAM banyak sekali memuat ungkapan bijak tentang perlunya bertanggung jawab dalam berbagai urusan. Di antara ungkapan TAM (1994: 204) tersebut adalah:

Wahai ananda permata hikmah tanggung jawabmu hendaklah ingat

berani menanggung sebab akibat

berani berbuat tahan dikebat

\section{Konstruksi Pendidikan} Karakter Berdasarkan TAM

1. Tujuan Pendidikan Berdasarkan TAM

$\begin{array}{rrr}\text { Tunjuk } & \text { Ajar } & \text { Melayu } \\ \text { menyatakan } & \text { bahwa } & \text { tujuan }\end{array}$
pendidikan yang paling utama adalah menjadi orang yang beriman dan beramal saleh.

Apa tanda Melayu beriman, menuntut ilmu di jalan Tuhan Apa tanda Melayu beriman, mencari ilmu jadi amalan Apa tanda Melayu beriman, mencari ilmu untuk pedoman 
Ungkapan di atas menunjukkan bahwa landasan pendidikan hendaklah selalu mengikuti pedoman yang telah ditetapkan dalam Islam. Selanjutnya ilmu yang sudah didapat hendaknya dijadikan pedoman dan pegangan serta diamalkan dalam kehidupan sehari-hari.

Kalau ilmu sudah di dada, gunakan ia di jalan Allah Kalau ilmu sudah melekat,manfaatkan untuk dunia akhirat.

\section{Materi Pendidikan Menurut TAM}

Materi pendidikan menurut TAM mencakup seluruh ilmu yang benar yang bersumber dari Allah Swt dan Rasululullah Saw. Ruang lingkup materi pendidikan menurut Tunjuk Ajar Melayu meliputi seluruh ilmu yang benar yang membawa manfaat bagi kebaikan manusia duniawi ukhrawi. TE (1994: 9)

apa isi tunjuk ajar Melayu, sari akidah, patinya ilmu Yang disebut ilmu bertuah, ilmu berpunca ke firman Allah Yang disebut ilmu sejati,ilmu mengandung firman Ilahi Yang disebut ilmu terpuji, di jalan Allah ia berdiri Yang disebut ilmu berkah,ilmu berpunca dari kitabullah
Yang disebut ilmu berkah, ilmu berwaris kepada sunnah.

\section{Proses Interaksi Belajar Mengajar Menurut TAM \\ Proses interaksi dalam} pendidikan menurut TAM haruslah memakai prinsip merata dan seimbang. Selain itu, antara guru dan murid harus saling terbuka dan menghormati.

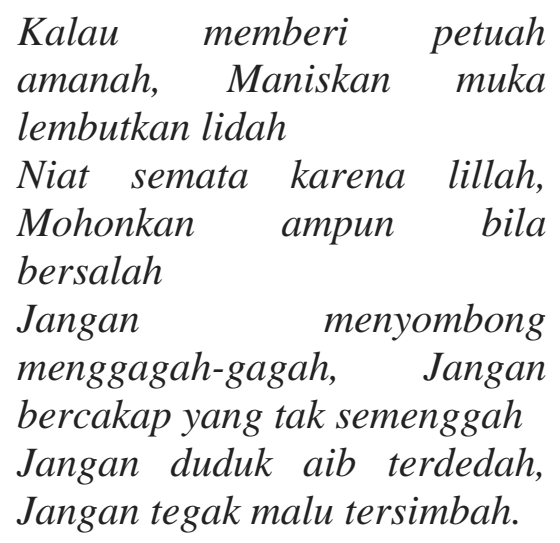

\section{Pendidik Menurut TAM}

Berkenaan dengan pendidik, TAM TE (1994: 580) menyatakan bahwa seorang pendidik mestilah berkarakter. Memiliki sifat-sifat terpuji seperti jujur dan lain sebagainya. Ia tidak boleh berpilaku buruk seperti suka menipu dan lain sebagainya karena keteladanan menjadi amat penting ketika menjadi pendidik. Patang berguru pada penipu/ Pantang belajar pada yang ingkar. Atau dalam ungkapan lain: 
Sebelum memberi petuah amanat/ diri sendiri elokkan tabiat.

\section{Anak Didik Menurut TAM}

Berkenaan dengan anak didik, banyak sekali terdapat pedoman yang diberikan dalam TAM (1994: 567), antara lain adalah:

Kalau hendak tahu adat berguru, tengok kepada tingkah dan laku

Kalau niat hendak berguru, jauhkan segala sifat pemalu Kalau niat hendak berguru, kebodohan diri sadari dulu Kalau niat hendak berguru, elokkan tingkah baikkan laku Kalau niat hendak berguru jauhkan sifat degil dan dakar Kalau niat hendak belajar, tinggalkan sifat berkepala besar

Kalau niat hendak belajar, kuatkan hati banyakkan sabar.

Dalam ungkapan lain Tenas Effendy (1994:20) juga

menyebutkan:

Adat duduk dalam mengaji, jauhkan sifat yang tak terpuji Adat duduk menuntut ilmu, jauhkan sifat malas dan jemu Adat duduk mencari petuah, waktu dijaga hati pun tabah Adat duduk mencari amanah, banyakkan ingat kepada Allah

\section{Metode Pendidikan Menurut TAM}

Metode pendidikan dalam TAM (1994: 20) disebutkan harus dengan bertahap. Selain itu, pendidikan hendaknya dilakukan dengan tepat dengan melihat situasi dan kondisi. Hal ini dapat dilihat dari ungkapan berikut:

Kalau memberi tunjuk ajar, Jangan lari bagai dikejar Bila memberikan tunjuk ajar, tengoklah patut dengan layaknya,

Tengoklah tempat dengan letaknya, tengoklah faedah dengan manfaatnya

Selain itu, TE (1994: 586) menyebutkan bahwa dalam mendidik hendaklah arif dan bijak, seperti ungkapan tunjuk ajar berikut:

Melandarayaya
jaga/Menampar supaya sadar
Memukul supaya
betu/Mengikat supaya ingat

7. Lingkungan Pendidikan

\section{Menurut TAM}

Zakiyah Daradjat (2016: 63) menyebutkan bahwa lingkungan dalam Pendidikan Islam juga sangat berpengaruh, bahkan pengaruh lingkungan dalam pendidikan Islam memiliki dampak yang cukup besar. Karena pengaruh lingkungan memiliki peranan penting maka 
Jurnal Ilmu Budaya, Vol. 17, No. 1 Agustus Tahun 2020

\begin{tabular}{llll}
\hline lingkungan & harus & sangat & $\begin{array}{l}\text { Besar batang tempat } \\
\text { berlindung }\end{array}$ \\
diperhatikan. & Berkenaan dengan & Kuat akar tempat bersila
\end{tabular}

lingkungan pendidikan, Tunjuk Ajar

Melayu TE (1994: 470) menyatakan bahwa lingkungan pendidikan yang baik adalah yang dapat memberikan perlindungan dan berkualitas.

Kalau menurut petuah adat Banyaklah tempat boleh menepat

Pertama, raja yang berdaulat

Kedua, penghulu yang amanat

Ketiga, ulama yang beribadat

Keempat, dubalang yang kuat

Kelima, orang tua yang bersifat

Keenam, orang muda yang taat Ketujuh, orang yang tahu syarak dan adat

Selanjutnya dalam TAM juga dijelaskan bahwa lingkungan pendidikan yang baik menurut adalah lingkungan yang memberikan ketenangan, keadilan dan kebijaksanaan serta menjadi tempat untuk menimba ilmu.

Wahai Ananda dengarlah manat

Kalau bergaul di rantau orang Carilah orang yang bijaksana

Lautan akal landung bicara

Kepungan di tengah negeri

Tempat beramu panjang dan pendek

Rimbun daun tempat berteduh Rindang dahan tempat bergantung

\section{Posisi Pemikiran Tenas \\ Effendy dalam Kontelasi Pemikiran \\ Pendidikan}

\section{Karakter}

Orang Melayu tidak menafikan bahwa sebelum Islam masuk ke tanah ini telah hadir beberapa agama lainnya seperti Hindu, Budha dan lain sebagainya. Akan tetapi Islam merupakan agama yang sesuai dan sempurna bagi orang Melayu. Begitu juga halnya dengan pendidikan karakter perspektif Tenas Effendy yang identik dengan pendidikan Islam. Selain itu pendidikan karakter Melayu juga bersumber pada nilainilai asas budaya Melayu Riau dan nilai nilai-nilai luhur budaya Melayu. Nilai-nilai itulah yang menjadi dasar membangun peradaban Melayu. Nilai-nilai asas tersebut di antaranya adalah, seperti nilai keterbukaan, nilai keislaman, nilai senenek dan semoyang, nilai seaib dan semalu, nilai senasib sepenanggungan, dan lain-lain. Sedangkan Nilai-nilai luhur tersebut seperti nilai sifat asal mula jadi, tahu berpegang pada yang satu, 
sifat tahu membalas budi, sifat hidup bertenggangan, mati berpegangan, sifat tahu 'kan bodoh diri, sifat tahu diri, dan lain-lain.

\section{Simpulan}

Tunjuk Ajar Melayu karya Tenas Effendy mengandung makna yang sangat komprehensif meliputi inti ajaran dasar agama Islam yang merupakan sumber pendidikan karakter. Bentuk pendidikan karakter yang terdapat dalam Tunjuk Ajar Melayu mencakup seluruh bentuk pendidikan karakter yang telah ditetapkan dalam pendidikan saat ini. Bentuk-bentuk pendidikan karakter dalam Tunjuk Ajar Melayu meliputi religiusitas, kejujuran, toleransi, disiplin, kerja keras, kretivitas, kemandirian, demokrasi, semangat kebangsaan, cinta tanah air, prestasi, kounikatif dan bersahabat, cinta damai, gemar membaca, peduli lingkungan, peduli sosial, dan tanggung jawab. Selain itu, dalam Tunjuk Ajar Melayu juga terdapat bentuk pendidikan karakter seperti keadilan, keberanian, kepribadian yang kuat, pemaaf, syukur, dan kesederhanaan. Bentuk pendidikan karakter dalam Tunjuk Ajar Melayu lebih komprehensif dibanding konsep pendidikan karakter yang ada karena Tunjuk Ajar Melayu menawarkan bukan hanya sekedar konsep, tetapi sampai kepada teknis yang tertuang dalam berbagai ungkapan yang mudah dipahami dan bisa dilaksanakan secara langsung oleh siapapun juga. Hal ini disebabkan konsep yang ditawarkan dalam Tunjuk Ajar Melayu sangat operasional walaupun jika dikaji lebih jauh, ungkapan tersebut memiliki makna yang luas dan mendalam.

Berdasarkan analisis terhadap bentuk pendidikan karakter dalam Tunjuk Ajar Melayu, maka dapat dibuat konstruksi pendidikan karakter berdasarkan unsur-unsur yang terdapat dalam pendidikan yakni tujuan pendidikan, pendidik, anak didik, materi/kurikulum, metode, dan lingkungan pendidikan. Implikasinya ke dalam tujuan yakni hendaknya pendidikan bertujuan menjadikan anak didiknya orang yang mengenal Allah Swt. Dengan mengenal Allah Swt, maka ia akan selalu mendekatkan diri kepada-Nya 
melalui ibadah wajib dan sunah yang ia kerjakan. Kurikulum juga harus mengarahkan anak didik kepada manusia yang berahlakul karimah baik dalam hubungan sesama manusia maupun hubungan dengan Allah Swt. Sejalan dengan tujuan, maka isi pendidikan harus mencakup materi-materi yang komprehensif seperti materi aqidah, ibadah, ahlak dan muamalah atau mencakup materi ilmu abadi (perennial) dan ilmu dicari (acquired). Berkaitan dengan metode, maka pendidikan hendaknya mengandung metode pembelajaran yang mengutamakan kelembutan serta kejelasan dalam penerapannya dan yang lebih penting adalah metode demonstrasi, diskusi, discovery, inquiry dan latihan. Lingkungan pendidikan hendaknya mencerminkan lingkungan yang demokratis dan terbuka. Pendidik yang diinginkan adalah pendidik yang cerdas, inovatif dan kreatif tetapi juga seorang yang pemaaf dan rendah hati. Selanjutnya anak didik yang dikehendaki adalah anak didik yang rajin, pekerja keras, tekun, cermat serta rendah hati.
Posisi pemikiran pendidikan karakter Tenas Effendy dilihat dari sudut pandang pemikiran barat dan Islam adalah lebih cenderung ke Islam. Namun demikian, nilai-nilai baik dalam persfektif barat juga tercakup dalam pemikiran Tenas Effendy. Orang Melayu tidak menafikan bahwa sebelum Islam masuk ke tanah ini telah hadir beberapa agama lainnya seperti Hindu, Budha dan lain sebagainya. Akan tetapi Islam merupakan agama yang sesuai dan sempurna bagi orang Melayu. Begitu juga halnya dengan pendidikan karakter perspektif Tenas Effendy yang identik dengan pendidikan Islam. Selain itu pendidikan karakter Melayu juga bersumber pada nilai-nilai asas budaya Melayu Riau dan nilai nilainilai luhur budaya Melayu. Nilainilai itulah yang menjadi dasar membangun peradaban Melayu. Nilai-nilai asas tersebut adalah, seperti nilai keterbukaan, nilai keislaman, nilai senenek dan semoyang, dan nilai lainnya. Sedangkan Nilai-nilai luhur tersebut seperti nilai sifat asal mula jadi, tahu 
Jurnal Ilmu Budaya, Vol. 17, No. 1 Agustus Tahun 2020

berpegang pada yang satu, sifat tahu

membalas budi, dan nilai lainnya.

\section{Daftar Pustaka}

Wibowo, Agus. 2014. Pendidikan Karakter di Perguruan Tinggi: Membangun Karakter Ideal Mahasiswa di Perguraun Tinggi. Yogyakarta: Pustaka Pelajar.

Venus, Antar. 2015. Filsafat Komunikasi Orang Melayu. Bandung: Simbiosa Rekatama Media.

Daradjat, Zakiyah. 2016. Ilmu Pendidikan Islam. Jakarta: Bumi Aksara.

Effendy, Tenas. 1994. Tunjuk Ajar Melayu (Butir-Butir Budaya Melayu Riau). Yogyakarta: Balai Kajian dan Budaya Melayu Bekerjasama dengan Adicita.

M Nur, Rohinah. 2011. Pendidikan Karakter Berbasis Sastra: Solusi Pendidikan Moral yang Efektif. Yogyakarta: ArRuzz Media. 